\title{
A roadmap for rapid decarbonization
}

Johan Rockström1, Owen Gaffney1,2, Joeri Rogelj3,4, Malte Meinshausen5,6, Nebojsa Nakicenovic3, Hans Joachim Schellnhuber 1,5

1Stockholm Resilience Centre, Stockholm University, 11418 Stockholm, Sweden.

2Future Earth, The Royal Swedish Academy of Sciences, 10405 Stockholm, Sweden.

3International Institute for Applied Systems Analysis, 2361 Laxenburg, Austria.

4ETH Zurich, 8092 Zurich, Switzerland.

5Potsdam Institute for Climate Impact Research, 14473 Potsdam, Germany.

6Australian-German Climate and Energy College, School of Earth Sciences, University of Melbourne, Victoria 3010, Australia.

\section{Main text}

Although the Paris Agreement's goals (1) are aligned with science (2) and can, in principle, be technically and economically achieved (3), alarming inconsistencies remain between science-based targets and national commitments. Despite progress during the 2016 Marrakech climate negotiations, long-term goals can be trumped by political short-termism. Following the Agreement, which became international law earlier than expected, several countries published mid-century decarbonization strategies, with more due soon. Model-based decarbonization assessments (4) and scenarios often struggle to capture transformative change and the dynamics associated with it: disruption, innovation, and nonlinear change in human behavior. For example, in just 2 years, China's coal use swung from 3.7\% growth in 2013 to a decline of 3.7\% in 2015 (5). To harness these dynamics and to calibrate for short-term realpolitik, we propose framing the decarbonization challenge in terms of a global decadal roadmap based on a simple heuristic - a "carbon law" - of halving gross anthropogenic carbon-dioxide ( $\mathrm{CO} 2$ ) emissions every decade. Complemented by immediately instigated, scalable carbon removal and efforts to ramp down land-use $\mathrm{CO} 2$ emissions, this can lead to net-zero emissions around mid-century, a path necessary to limit warming to well below $2^{\circ} \mathrm{C}$.

The Paris goal translates into a finite planetary carbon budget: a $50 \%$ chance of limiting warming to $1.5^{\circ} \mathrm{C}$ by 2100 and a $>66 \%$ probability of meeting the $2^{\circ} \mathrm{C}$ target imply that global CO2 emissions peak no later than 2020, and gross emissions decline from $\sim 40$ gigatons (metric) of carbon dioxide (GtCO2)/year in 2020, to $\sim 24$ by 2030, $\sim 14$ by 2040, and $\sim 5$ by 2050 (3) (see the figure, top). Risks could be further reduced by moderately increasing ambition to halve emissions every decade (see the figure, bottom right). Following such a global carbon law means at least limiting cumulative total CO2 emissions from 2017 until the end of the century to $700 \mathrm{GtCO} 2$, which allows for a small but essential contingency ( $125 \mathrm{GtCO} 2$ less compared with total CO2 emissions in the pathway in the figure, top) for risks of biosphere carbon feedbacks (6) or delay in ramping up CO2-removal technologies.

A carbon law applies to all sectors and countries at all scales and encourages bold action in the short term. It means, for example, doubling of zero-carbon shares in the energy system every 5 to 7 years, a rate consistent with the trajectory of the past decade (see the figure, bottom left). All sectors (e.g., agriculture, construction, finance, manufacturing, transport) need comparable transformation pathways. In addition, in the absence of viable alternatives, the world must aim at rapidly scaling up $\mathrm{CO} 2$ removal by technical means from zero to at least $0.5 \mathrm{GtCO} /$ year by 2030, 2.5 by 2040, and 5 by 2050. $\mathrm{CO} 2$ emissions from land-use must decrease along a nonlinear trajectory from $4 \mathrm{GtCO} 2 /$ year in 
2010, to 2 by 2030, 1 by 2040, and 0 by 2050 (see the figure, bottom right). The endgame is for cumulative $\mathrm{CO} 2$ emissions since 2017 to be brought back from around $700 \mathrm{GtCO} 2$ to below 200 GtCO2 by the end of the century (see the figure, top) and atmospheric $\mathrm{CO} 2$ concentrations to return to $380 \mathrm{ppm}$ by 2100 (currently at $400 \mathrm{ppm}$ ).

Roadmaps are planning instruments, linking shorter-term targets to longer-term goals. They help align actors and organizations to instigate technological and institutional breakthroughs to meet a collective challenge. An explicit carbon roadmap for halving anthropogenic emissions every decade, codesigned by and for all industry sectors, could help promote disruptive, nonlinear technological advances toward a zero-emissions world. The key to such a carbon law will be a dual strategy that pushes renewables and other zeroemissions technologies up the creation and dissemination trajectory, while simultaneously pulling fossil-based value propositions from the market. Thus, the transformation unfolds at a pace governed by novel schemes rather than by inertia imposed by incumbent technologies (see the figure, bottom left).

We sketch out a broad decadal decarbonization narrative in four dimensions-innovation, institutions, infrastructures, and investment-to provide evidence of feasibility and depth of transformation for economies to stay on a carbon-law trajectory. The narrative provides no guarantees but identifies crucial steps, grounded in published scenarios combined with expert judgment. Each step has two parts: actions for rapid near-term emissions reductions, and actions for systemic and long-term impact, creating the basis for the next steps. Such a narrative, specifically designed with decadal targets and incentives, could provide key elements for national and international climate strategies.

\section{7-2020: No-Brainers}

Annual emissions from fossil fuels must start falling by 2020. Well-proven (and ideally incomeneutral) policy instruments such as carbon tax schemes, cap-and-trade systems, feed-in tariffs, and quota approaches should roll out at wide scale. Even these will be challenging in the emerging global political climate. The European Union emissions-trading scheme requires kick-starting through an appropriate floor price ( $\$ 50 /$ metric ton $\mathrm{CO} 2$ ).

The United Nations Framework Convention on Climate Change (UNFCCC) should transform into a vanguard forum where nations, businesses, nongovernmental organizations, and scientific communities meet to refine the roadmap. It is evident that the current national commitments under the Paris Agreement must be strongly enhanced at the first ratcheting-up cycle in 2018 to 2020.

Fossil-fuel subsidies, currently $\$ 500$ billion to $\$ 600$ billion per annum, must be eliminated by 2020 , not 2025 as agreed by the Group of Seven (G7) nations in 2016. An immediate moratorium on investment in new unabated coal-based energy would minimize future stranded assets. China's greenhouse gas (GHG) output must continue to decrease over the coming years, through aggressive funding of renewables, by abandoning coal expansion, and by closing mines. The richer coal-intensive countries must spearhead the coal exit, and countries like India and Indonesia must follow suit.

By 2020, all cities and major corporations in the industrialized world should have decarbonization strategies in place. The 49 countries already committed to be carbon neutral by 2050 should have expanded to $>100$ countries by that time, and implementation should be under way. The gravest risk is that emerging economies, such as South Africa, are driven down the conventional growth path by sheer inertia. International efforts must incentivize low-carbon development as a priority.

Food production contributes to $>10 \%$ of global GHG emissions (4) and weakens natural carbon sinks yet has vast potential for biological carbon removal. Innovative financial mechanisms are needed to incentivize carbon management in the food system. Agro-industries, farms, and civil society should 
develop a worldwide strategy for sustainable food systems to drive healthier, low-meat diets (7) and reduce food waste (8). Health and sustainability cobenefits-such as obesity and disease abatement, pollution reduction, and ecosystems preservation-should spur action.

\section{0-2030: Herculean Efforts}

Economies must implement the no-brainer mitigation measures plus the first wave of smart and disruptive action. Improving energy efficiency alone would reduce emissions 40 to $50 \%$ by around 2030 in many domestic and industrial cases (9).

In the 2020s, carbon pricing across the world must expand to cover all GHG emissions, starting at $\$ 50$ per metric ton at least and exceeding $\$ 400$ per ton by mid-century. By the end of that decade, coal will be about to exit the global energy mix, cities like Copenhagen and Hamburg will be fossil-fuel free, and cap-and-trade regimes should be firmly established across national and regional economic zones along with adequate carbon taxes on air transport and shipping. Countries should follow Norway, Germany, and the Netherlands and announce the phase-out of internal combustion engines in new cars by 2030 at the latest. Decarbonizing long-distance transport will be key, through renewable fuels, electrification, and replacing shorter-haul air traffic by rapid rail. These commitments will signal that the conventional model of reinvesting fossil-fuel revenues into exploration is obsolete.

Public and private investment in research and development (R\&D) for climate solutions should increase by an order of magnitude between now and 2030. Substantial resources must be directed toward more efficient modes of industrial production; battery-life extension and improved energy storage solutions; schemes that greatly reduce the cost of carbon capture and storage (CCS) within 10 years; alternative aircraft propulsion systems; super-smart power grids; and sustainable urbanization everywhere.

We need urgent research to ascertain the resilience of remaining biosphere carbon sinks (10). Strong financial impetus must be provided for afforestation of degraded land and for establishment of noregret approaches to net removal of $\mathrm{CO} 2$ from the atmosphere-such as the combination of secondand third-generation bioenergy with CCS (BECCS) or direct air CCS (DACCS). Trials of sustainable sequestration schemes of the order of 100 to $500 \mathrm{MtCO} /$ year should be well under way to resolve deployment issues relating to food security, biodiversity preservation, indigenous rights, and societal acceptance.

\section{0-2040: Many Breakthroughs}

By 2040, oil will be about to exit the global energy mix. Several vanguard countries (such as Norway, Denmark, and Sweden) should have completed electrification of all sectors and be entirely emissions-free or close to it. Internal combustion engines for personal transport will have become rare on roads worldwide. Aircraft fuel should be entirely carbon neutral. Synthesized fuels, biomethane, and hydrogen are established alternatives.

After 2030, all building construction must be carbon-neutral or carbon-negative. The construction industry must either use emissions-free concrete and steel or replace those materials with zero- or negative-emissions substances such as wood, stone, and carbon fiber.

BECCS schemes totaling 1 to $2 \mathrm{GtCO} /$ year would roll out, and R\&D should focus on doubling the annual rate of $\mathrm{CO} 2$ removal. We can expect that polycentric power grids using supraconductive cables will start supplying energy in developing countries, and radical new energy generation solutions will enter the market. 
Promising financial mechanisms to foster investments in necessary breakthroughs include sovereign wealth funds designed for transformation; effective international corporation tax regimes (11); and inheritance reforms that account for historical wealth generated by fossil fuels without compensation of externalities (12).

\section{0-2050: Revise, Reinforce}

Building on successes and learning from failures of previous stages, certain mitigation strategies will be abandoned and others refined and amplified. All major European countries become close to netzero carbon states early in the 2040s; market dynamics push North and South America and most of Asia and Africa to this goal by the end of the decade. Natural gas still provides some backup energy, but CCS ensures its carbon footprint is limited. Modular nuclear reactors may contribute to the energy mix in places.

By 2050, the world will have reached netzero CO2 emissions, with a global economy powered by carbon-free energy and fed from carbon-sequestering sustainable agriculture. Meanwhile, BECCS schemes have been scaled up and draw down $>5 \mathrm{GtCO} 2 /$ year. Alternatively, concerns may rule out such scale-up. Only deep emission reductions during 2020-2030 can enable BECCS to be scaled back or abandoned, while efforts to increase energy efficiency and DACCS continue.

\section{Stability and Resilience}

We cannot predict where civilization will be mid-century, but a decadal staircase based on a carbon law, if adopted broadly, may provide essential economic boundary conditions to make a zeroemissions future an inevitability rather than wishful thinking. The very nature of disruptive progress requires revising the narrative of a detailed roadmap every 2 years, correcting near-term targets to reach the ultimate goal by evolutionary management.

Although signs are positive that the world is on track to rapidly transform to a net-zero-emissions global economy, contagion dynamics cut both ways. If political signals do not support a rapid transition, for example, by a failure to implement worldwide financial and regulatory reform that places a cost on carbon, then it is difficult to imagine keeping warming at "well below $2^{\circ} \mathrm{C}$." However, the scale of momentum toward clean energy in the past decade suggests that it would seem foolish to try to halt the trend, given the growing evidence that decarbonization can be a major progrowth strategy.

In global governance, climate stabilization must be placed on par with economic development, human rights, democracy, and peace. The design and implementation of the carbon roadmap should therefore take center stage at the UN Security Council, as these quintessential objectives increasingly interact, influencing the stability and resilience of societies and the Earth system.

\section{References}

UNFCCC, Paris Agreement (2015).

H. J. Schellnhuber, S. Rahmstorf, R. Winkelmann, Nat. Clim. Chang. 6, 649 (2016).

J. Rogelj et al., Nat. Clim. Chang. 5, 519 (2015).

Intergovernmental Panel on Climate Change, Climate Change 2014: Mitigation of Climate Change: Working Group III Contribution to the Fifth Assessment Report of the Intergovernmental Panel on Climate Change, O. Edenhofer et al., Eds. (Cambridge Univ. Press, Cambridge, 2014).

B. P. Global, BP Statistical Review of World Energy (BP Global, ed. 65, 2016). 
P. Ciais et al., in Climate Change 2013: The Physical Science Basis: Working Group I Contribution to the Fifth Assessment Report of the Intergovernmental Panel on Climate Change, T. F. Stocker et al., Eds. (Cambridge Univ. Press, Cambridge, 2013), pp. 465-570.

K.-H. Erb et al., Nat. Commun. 7, 11382 (2016).

C. Hiç et al., Environ. Sci. Technol. 10.1021/acs.est.5b05088 (2016).

Global Energy Assessment Writing Team, Global Energy Assessment: Toward a Sustainable Future (Cambridge Univ. Press, Cambridge, and the International Institute for Applied Systems Analysis, Laxenburg, Austria, 2012).

P. Williamson, Nature 530, 153 (2016).

T. Piketty, Capital in the 21st Century (Harvard Univ. Press, Cambridge, MA, 2013).

German Advisory Council on Global Change, Development and justice by transformation: The big four I's (WBGU, Berlin, Germany, 2016).

M. Meinshausen, S. C. B. Raper, T. M. L. Wigley, Atmos. Chem. Phys. 11, 1417 (2011). 